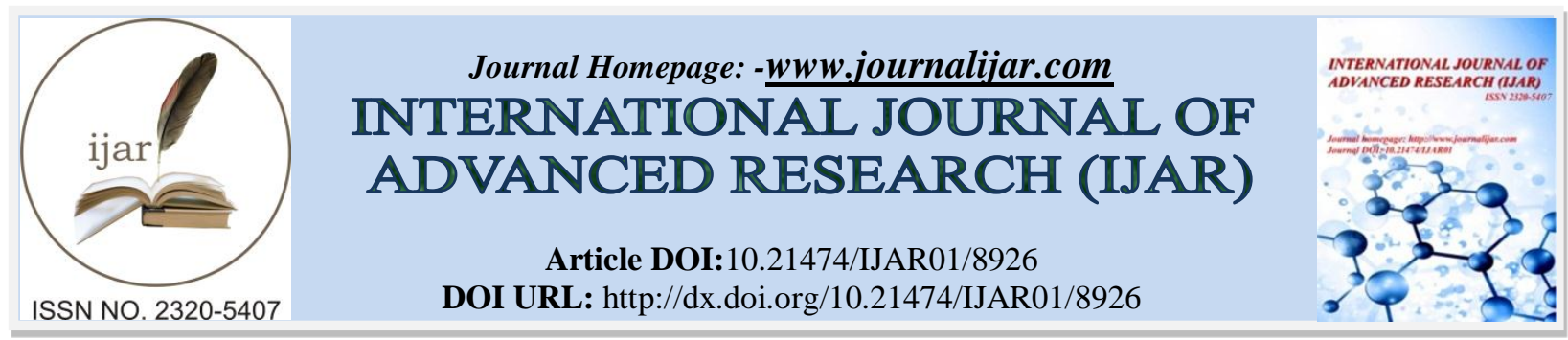

RESEARCH ARTICLE

\title{
STRESS TESTING FOR LIQUIDITY RISK MANAGEMENT CASE OF CDG CAPITAL IN MOROCCO.
}

Ezouine Driss and El Haddad Mohamed Yassine.

Department of Management-Faculty of Juridical, Economical and Social Sciences University of Mohamed 5, Rabat, Morocco.

\section{Manuscript Info}

Manuscript History

Received: 21 February 2019

Final Accepted: 23 March 2019

Published: April 2019

\begin{abstract}
In response to the financial crisis and its repercussions on financial institutions, the new regulatory requirements relating to the management of bank liquidity have been introduced. For a better management of the liquidity risk, and a more adequate estimate of the potential risk incurred by the bank CDG Morocco, the stress tests represent a method for a precise evaluation of the risk. Liquidity risk is an important risk class, it needs its own risk measures such as the net stable financing rate (NSFR) and Liquidity Coverage Ratio (LCR) as prescribed by the Basel Committee on Banking Supervision (BCBS). The purpose of this paper is to study the liquidity of the CDG bank by the stress test technique to make decisions on the financial state of the bank.
\end{abstract}

\section{Introduction:-}

Stress tests is a term that describes a series of techniques used to assess a portfolio's vulnerability to major changes in the macroeconomic environment or to exceptional but plausible events. They were originally developed for use at the portfolio level, to understand how the value of a portfolio changes if there are significant changes to its risk factors (such as asset prices).

Stress tests are quantitative tools used by bank supervisors and central banks to assess the soundness of financial systems in the case of extreme shock, but still plausible (macroeconomic stress tests). They are also an important management tool for banks as they provide financial institutions with useful insights into the reliability of internal systems designed for risk measurement (microeconomic or prudential stress tests).

Until the first half of 2007, interest in stress testing had been limited to practitioners, namely risk managers or even central banks and financial supervisors. Since then, the global financial system has been affected by deep turbulence and all major economies have been affected by high volatility in the financial markets, deteriorating portfolio values, widespread renegotiation of risks and liquidity drying up. severe (see Appendix 1). It was pointed out that the severity of the crisis was largely due to its unexpected nature and that a more thorough and rigorous use of stress test methodologies would probably have helped to mitigate the intensity and impact of the crisis. crisis. The first section is an introduction to stress tests which includes the conceptual framework of the stress test, a literature review and a simulation of the liquidity stress test. In the second section, we discuss the role and coverage of a stress test. The third section discusses the typologies of a stress test. Finally, in the fourth section we will talk about the methodology of conduct of stress tests in the CDG Morocco bank. 


\section{Literature review \\ Stress tests: Conceptual framework}

According to the Committee on the Global Financial System (2005), stress-testing is a risk management tool used to assess the potential impact on a business of a specific event and / or movement in a set of financial variables. As a result, stress-testing is used as an adjunct to statistical models such as Value-at-Risk (VaR), and increasingly, it is considered a complement rather than a supplement, to these measures. statistics.

Some authors consider stress tests as a subgroup of risk modeling with a focus on "tail" events that is complementary to "conventional" methods such as Value at Risk (VaR) and should be included in a global risk model ${ }^{1}$. Others see stress testing as a separate approach that goes beyond the past shock distribution used in VaR and is more of an "art" than a science - (Kupiec, 1995) [1]. The IMF ${ }^{2}$ considers stress-testing from a macroeconomic point of view and defines it as a key element of macroprudential analysis that tracks and anticipates potential vulnerabilities in the financial system. Stress tests also focus on vulnerabilities ${ }^{3}$ of the financial system, including the banking system, macroeconomic and sectoral shocks.

\section{Review of the literature on stress tests of the banking sector}

The first models of stress tests in the banking sector, which were initially based on simple historical scenarios linking macroeconomic developments with variables in the financial sector (Blaschke et al., 2001) [2], have been developed in more sophisticated models integrating the risks of market rates, credit and interest and the capture of interinstitutional contagion and feedback effects between the financial sector and the real economy. These relatively complex models have become regular tools for analyzing the resilience of the financial sector - see, for example, Denmark's National Bank (2010, p. 45), Oesterreichische National Bank (2010, p. 51), Norway Bank (2010, p. 49.), the Bank of England's RAMSI (Systemic Risk Assessment Model for Institutions) (Aikman et al., 2009) [3], and the ECB (2011) [4]. Nevertheless, the global financial crisis has revealed deficiencies in the stress testing methodologies used in many countries. Before the crisis, many tests led to the mistaken belief that the sector should remain stable even in the event of major shocks (Haldane, 2009). [5]; Borio \& al, 2012) [6]. These deficiencies are not only related to the unfavorable scenario configuration used, which initially seemed unlikely, but were often exceeded in reality, but also to the supposed combination of shocks, which had not been sufficiently anticipated in the scenarios (Ong and Čihák, 2010 [7]; Breuer \& al., 2009) [8].

A role is also played by deficiencies in the calibration of the model and the presumed behavior of banks and markets, and in the absence of liquidity stress tests that go with other types of traditional financial risks (notably credit risk and credit risk). interest rate risk). The panic after the fall of Lehman Brothers ${ }^{4}$ confirmed the importance of the spiral between the market and the liquidity of funding and its frail link to the solvency of institutions (Gorton, 2009 [9]; Brunner Meier \& al, 2007.) [10]. This problem in stress-testing devices is also demonstrated by Ong and Čihák (2010) [11] using the example of Iceland, where the banking sector collapsed in the autumn of 2008, even though stress tests conducted in mid-2008 had indicated that it was stable and resistant to various shocks. As a result, the assumptions and parameters used in stress tests are progressively re-examined so that the tests can better understand the impact of violent shocks on the financial system. Stress testing is becoming a standard tool in the new macroprudential framework (FSB 2011 [12]; BCBS, 2012) [13], but there are doubts about their ability to serve as an early warning device ${ }^{5}$. Yet, despite a clear consensus on the importance of stress testing, there are many disadvantages associated with methodological approaches to stress and the construction of valid and severe scenarios (Jakubík and Sutton, for example) 2012) [14].

Buncic and Melecky (2012) [15] give some practical suggestions on some of these difficulties (such as how to construct stress scenarios if there are no stress periods in the estimation sample) and to provide an empirical application of the proposed method for the banking sector of a country in Eastern Europe. Still, stress tests are a relatively new tool and could therefore experience significant methodological development and refinement in the future. The recent financial turmoil has suggested some ways in which this methodological development should be directed. A recent report published by the Basel Committee on Banking Supervision (BCBS, 2012) [16] on best

\footnotetext{
1 Berkowitz, 1999

2 voir Sundararajan et al., 2002

3 Voir Haldane 2009a and 2009b

4 Brunnermeier et al, 2009

5 Borio et al, 2012
} 
practices in macroprudential analysis highlighted the need to overcome the bias of the potential decline in risk estimation during the use of estimated models on quiet period data.

\section{Simulations of liquidity stress tests}

A liquidity stress test examines whether financial institutions have sufficient cash and cash inflows to withstand cash outflows in a stress scenario. Financial institutions may experience sudden cash outflows, for example, because of:

1. Sudden suffering of their funding ${ }^{6}$.

2. The interconnections between the market liquidity of assets and the liquidity of financing.

3. A lack of liquidity for financial institutions when they can no longer generate enough liquidity to respond to a shock.

\section{Coverage of a stress test}

Coverage of stress tests ${ }^{7}$ has increased beyond the basic risk assessment. On the asset side, stress tests tend to focus on tradable market portfolios. On the liability side, funding liquidity for individual institutions is stressed at different levels. Scenarios include changes in: customer behavior; credits, financing costs and warranty requirements.

\section{The role of a stress test}

Stress testing is a risk management tool used to evaluate the potential impact of a specific event and / or movement in a set of financial variables on a company. As a result, stress tests are used as adjunct to statistical models such as value at risk (VaR), and increasingly, it is considered a supplement rather than a supplement to these statistical measures. Stress tests are generally divided into two categories: scenario tests and sensitivity tests. In scenario stress tests, the source of the shock, or the stress event, is well defined, as are the financial risk parameters that are affected by the shock. On the other hand, the sensitivity tests specify the financial risk parameters, the source of the shock is not identified.

Stress can: capture the impact of large but plausible large claims on a portfolio and allow us to understand the risk profile of the firm through a risk assessment of the company.

\section{Typology of stress tests}

The microprudential stress tests ${ }^{8}$ emphasize the traditional role of bank capital as a buffer against loss. Table 1 describes the five main features of a microprudential test.

Table1:-Elements of a microprudential stress test

\begin{tabular}{|l|l|}
\hline Goal & $\begin{array}{l}\text { The goal is to assess bank holdings properly and to determine that the ability to assume the } \\
\text { appropriate loss is in place to protect taxpayers from having to bail out insured deposits. }\end{array}$ \\
\hline Scope & $\begin{array}{l}\text { Analyze one bank at a time, or use data from multiple banks to overcome information } \\
\text { imperfections on the asset values of individual banks. }\end{array}$ \\
\hline $\begin{array}{l}\text { Deposit } \\
\text { Considerations }\end{array}$ & $\begin{array}{l}\text { Count the amount of insured deposits and the amount of subordinated debt and equity. The } \\
\text { required loss absorption is calculated as a ratio to the risk of the asset. }\end{array}$ \\
\hline $\begin{array}{l}\text { Asset } \\
\text { Considerations }\end{array}$ & $\begin{array}{l}\text { The credit risk of different assets determines the risk of the business, so that the loss of } \\
\text { commitment absorption is linked to the asset mix. A capital ratio therefore naturally emerges as a } \\
\text { basis for supervision. }\end{array}$ \\
\hline Output & Develop guidance on closing a bank and when to sell assets to maximize taxpayer recovery. \\
\hline
\end{tabular}

Source: Stressed Out: Macroprudential Principles for Stress Testing Working Paper No:71. Chicago Booth Paper No.12

Macroprudential stress tests are based on the idea that an economy must maintain the ability of its banking sector to channel savers' deposits to borrowers for support of real economic activity. The main fear is that individual middlemen, when struck with a common shock, will jostle for survival by reducing their deposits ${ }^{9}$.

Mitigating damage from asset liquidation, credit tightening and repayment defaults is a central goal of macroprudential regulation. Macroprudential Stress Test Naturally Serves as Part of the Macroprudential Toolkit ${ }^{10}$.

6 Schmieder et al. 2012

7 http://www.c-ebs.org/documents/GL03stresstesting.pdf

8 See the survey of the BCBS (2012)

9 See Greenlaw, Hatzius, Kashyap and Shin (2008) for a model showing how the depreciation of capital to leveraged financial intermediaries can lead to a contraction magnified the availability of credit, Hirtle, Schuermann and Stiroh (2009) state that the American stress test included the macroprudential objective of facilitating all loans.. 


\section{Stress management stress tests}

Stress tests were also used, especially after the recent crisis, to assess whether key financial institutions should be recapitalized or not, possibly with the support of the public authorities. In recent IMF programs with distressed banking sector (including Ireland, Greece ${ }^{11}$ and Portugal), estimating bank recapitalization needs through stress tests is an important element. Since the use of stress tests as a crisis management tool is relatively new, Table 10 presents the main characteristics, the similarities with, and the differences of the other types of stress tests, using three recent examples of this type. stress tests ${ }^{12}$ (SCAP US, CEBS / EBA tests in 2010 and 2011, and the 2012 EBA capital assessment exercise) as illustrations.

\section{Methodology:-}

\section{Stress testing of liquidity risk}

There are two main types of liquidity risk: Asset liquidity risk and financing liquidity risk. Asset liquidity risk refers to the inability to conclude a transaction at a certain price because of the size of the transaction. This type of liquidity risk will come into play when certain assets need to be liquidated quickly (a "liquidation of assets"). Financing liquidity risk refers to the inability to access sufficient funds to meet its timely payment obligations.

Banks are under constant liquidity pressure because of the nature of their business. Banks finance long-term loans with short-term liabilities, and maintain an unusually large portion of their liabilities in the form of outstanding debt. As a result, banks face liquidity pressures ${ }^{13}$ caused by imbalances between the maturity dates of their assets and their liabilities, which implies that cash inflows from assets cannot match cash outflows to cover commitments. Changes in interest rates can also lead to liquidity problems. A high interest rate can cause liquidity withdrawals as depositors look for higher returns elsewhere.

\section{Stress testing at the portfolio level}

Stress tests begin with the specification of the type of risks to be considered and the appropriate models to use. Stress tests can focus on individual risks, such as credit risk or interest rate risk, or can encompass multiple risks. Developing a scenario involves estimating or making assumptions about the interdependence between the main economic and financial factors that underlie it: interest rate, GDP, unemployment rate, share price, price index to the consumption, real estate prices. The selected scenario will be applied to all relevant positions (on and off-balance sheet) of the institution.

The next step in a stress test is to decide on the set of factors to include, followed by the scenario specification. Stress tests $^{14}$ may involve estimating the impact of a change in a single risk factor (a sensitivity test), or the effect of simultaneous movement in a group of risk factors (a scenario analysis). Stress tests may be based on historical scenarios, shocks that have occurred in the past, or may be based on hypothetical scenarios, constructed to account for plausible changes in circumstances that have no historical precedent.

\footnotetext{
10 See Kashyap; Berner and Goodhart (2011) and Goodhart; Kashyap, Tsomocos and Vardoulakis (2012) for additional tools that would complement the stress tests.

11 http://www.eba.europa.eu/News--Communications/Year/2011/The-EBA-publishes-Recommendation-and- finalresults.aspx.

12 In accordance with the agreements published by the Basel Committee on Banking Supervision (BCBS) in September and December 2010. See http://www.bis.org/press/p100912.htm

13 See IMF, 2008, 2010; Frank et al, 2008

14 Ong \& Čihàk (2010)
} 
Figure 1:-sequence of the course of a stress test

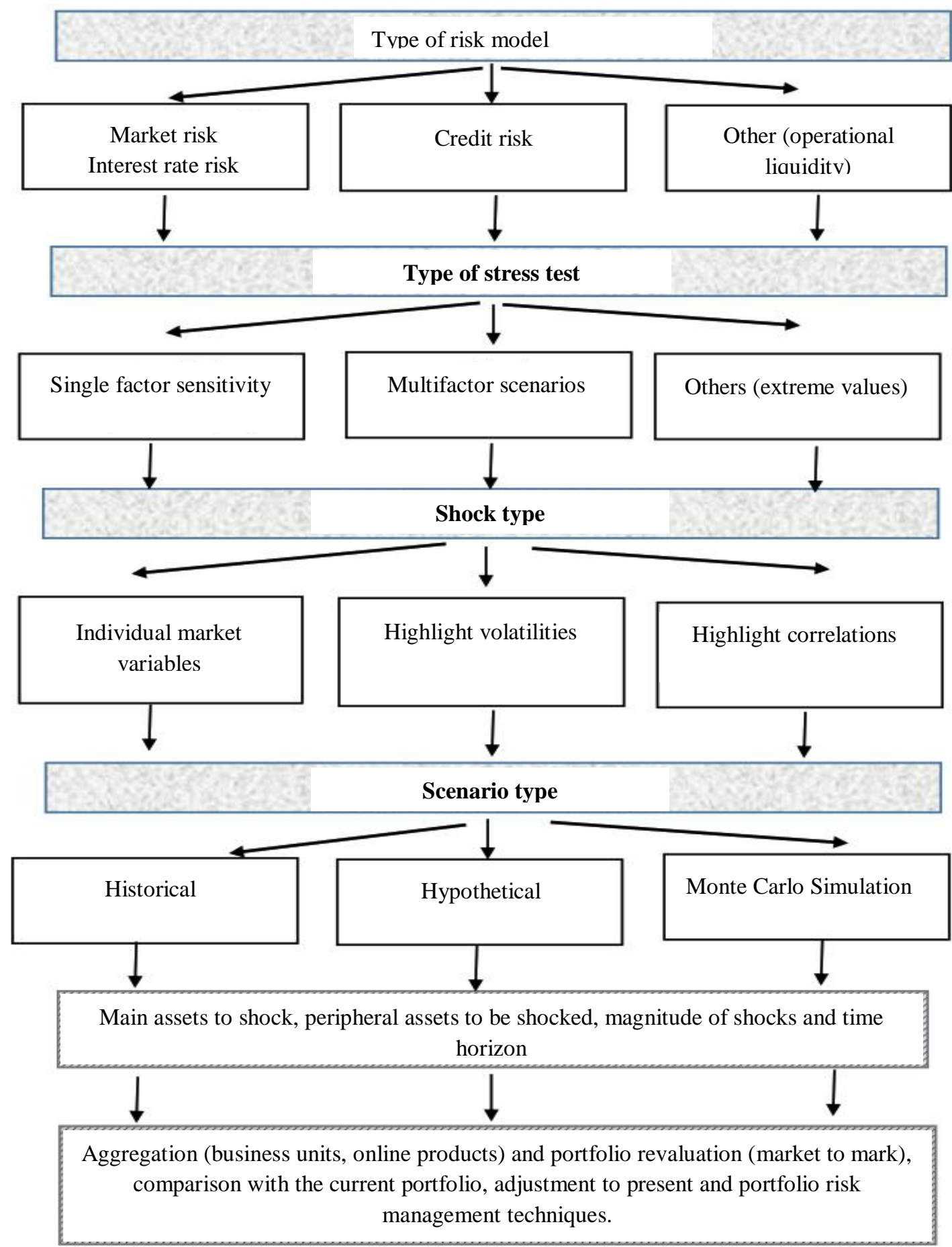

Source: Stress testing of financial systems an overview of issues, methodologies and FSAP experiencesing 


\section{Type of scenarios}

Historical scenarios:

Historical data is an important benchmark for liquidity risk stress tests. At a minimum, it is important that banks be able to withstand shocks of a magnitude similar to those that have occurred in the past. Similarly, in the case of developing countries, authorities can use withdrawals observed in other peer group countries in crisis situations as a reference.

\section{Hypothetical scenarios:}

Given the difficulty of modeling hypothetical scenarios based on macroeconomic scenarios: The hypothetical scenarios have the advantage of allowing a more flexible formulation of potential events, as well as encouraging risk managers to be more forward looking. Hypothetical scenarios can be constructed by extreme market factors (shocks), volatility, or correlations. This approach determines the sensitivity of a portfolio to different risk factors. The main disadvantage of hypothetical scenarios is the difficulty in determining the probability of occurrence of an event because it is beyond the scope of the experiment.

\section{Monte-Carlo simulation:}

Consists of repeatedly simulating the random process that governs prices and market rates. Each simulation (scenario) generates a possible value for the portfolio at the target horizon. If enough scenarios are generated, the simulated distribution of the value of the portfolio converges to the real distribution.

\section{Theory of extreme values:}

It is the statistical theory of the tails of the probability of distributions that tries to better identify the risks of loss in extreme circumstances. The advantage is that this method is not limited by the normal distribution assumption, and therefore can accommodate asymmetric and thick-tail portfolio change distributions. However, the approach assumes that extreme events are not correlated, which may not be true in reality, and therefore the consequences for the portfolio may be distorted.

\section{Sensitivity analyzes}

Sensitivity analysis involves applying simple stress to a risk factor considered in isolation to assess the institution's sensitivity to this risk factor. Institutions may consider, for example, a simple stress of interest rate change, a simple change in probabilities of default (PD), the default of their largest counterparties, or a decline in the value of assets. liquids. Such analyzes provide insights into key risks and provide a better understanding of potential risk concentrations associated with one or more factors.

As a first step, the institutions will determine the relevant risk factors, and in particular. Then, the institutions will be able to submit to more or less severe stress the risk factors identified.

The severity of the stress to be applied on a single factor will probably be influenced by the experience of long-term historical data.

\section{Top-down or bottom-up ${ }^{15}$ exercises}

Once a set of scenarios has been implemented in a coherent macroeconomic framework, the next step is to translate the different outputs into the balance sheets and profit and loss accounts of the financial institutions. There are two main approaches to translating scenarios into balance sheets: the bottom-up approach, where estimates are based on individual portfolio data, and the top-down approach, which uses data. aggregated or macroeconomic to estimate the impact.

\section{Test stress test application for the case of CDG capital.}

\section{Stress test of the liquidity coefficient}

The present liquidity stress tests are based on the balance sheet in December 2012. The assumptions are based on the different international approaches already in force. They are also based on a refined collar of different tests and simulations made by several international experts ${ }^{16}$. We have also taken into consideration the guidelines dictated by

15 Next Generation System-Wide Liquidity Stress Testing Christian Schmieder, Heiko Hesse, Benjamin Neudorfer, Claus Puhr, Stefan W. Schmitz 16 Martin Čihák IMF working paper WP/07/59 Introduction to Applied Stress Testing. 
the BAM directive on stress tests ${ }^{17}$, which presents a precise idea on the application and the implementation of a stress test device at the national level and on which one will be able to be based to carry out our own tests of stress tests.

\section{Data and results:-}

\section{V.1.1 Data presentation}

We see that liquid assets represent $145 \%$ of term deposits and are greater than all CDG capital deposits. This is due first of all to the nature of CDG capital which is an investment bank, and also to the fact that the Moroccan stock market is almost hibernating.

Table 2:-Basic data table for liquidity stress tests:Simple liquidity test (in thousands of dirhams)

\begin{tabular}{|l|l|l|l|}
\hline & Simple Scenario & Scenario Medium & High scenario \\
\hline Term deposit (domestic currency) & 1551078 & 1551078 & 1551078 \\
\hline Withdrawal per day (\%) & 5 & 20 & 90 \\
\hline Demand deposit (domestic) & 652316 & 652316 & 652316 \\
\hline Withdrawal per day (\%) & 20 & 40 & 65 \\
\hline Foreign currency deposit & 32847 & 32847 & 32847 \\
\hline Withdrawal per day (\%) & 30 & 50 & 70 \\
\hline Liquid assets & 2263093 & 2263093 & 2263093 \\
\hline Available per day (\%) & 40 & 55 & 30 \\
\hline Less active or non-liquid assets & 1809758 & 1809758 & 1809758 \\
\hline Available per day (\%) & 60 & 80 & 1 \\
\hline
\end{tabular}

\section{V.1.2 Presentation of the hypotheses}

We will consider three scenarios, a simple scenario with simple assumptions whose effects of liquidity risks are only slightly felt; a medium scenario with stronger effects and a high scenario with assumptions that represent extreme but plausible liquidity risk effects.

Assumptions for five-day term and demand deposit withdrawals (in both national and foreign currencies) are summarized in Table 3:

Table 3:-Assumptions for five-day term and demand deposit withdrawals (in both national and foreign currencies)

\begin{tabular}{|c|c|c|c|c|c|c|c|c|c|c|c|}
\hline \multicolumn{6}{|c|}{ A term deposit } & \multicolumn{6}{|c|}{ Demand deposit } \\
\hline Scenario & Day 1 & Day 2 & Day 3 & Day 4 & Day 5 & Scenario & Day 1 & Day 2 & Day 3 & Day 4 & Day 5 \\
\hline Simple & 10 & 10 & 20 & 75 & 65 & Simple & 95 & 90 & 85 & 70 & 60 \\
\hline Medium & 10 & 20 & 30 & 60 & 100 & Medium & 90 & 80 & 70 & 55 & 100 \\
\hline High & 20 & 35 & 45 & 100 & 100 & High & 75 & 70 & 55 & 100 & 100 \\
\hline \multicolumn{6}{|c|}{ Term deposit with foreign currency } & & & & & & \\
\hline Scenario & Day 1 & Day 2 & Day 3 & Day 4 & Day 5 & & & & & & \\
\hline Simple & 105 & 10 & 15 & 20 & 25 & & & & & & \\
\hline Medium & 10 & 25 & 35 & 45 & 60 & & & & & & \\
\hline High & 25 & 35 & 40 & 55 & 70 & & & & & & \\
\hline
\end{tabular}

The assumptions relating to the sales of CDG Capital's assets, as well as the respective haircuts, are also spread over five days and are summarized in Table 4:

Table 4:-table presenting the assumptions of stress test simulation of the liquidity ratio

\begin{tabular}{|l|l|l|l|l|l|l|l|l|l|l|l|}
\hline Liquid assets & Non-liquid assets \\
\hline Withdrawal & Day 1 & Day 2 & Day 3 & Day 4 & Day 5 & Scenario & Day 1 & Day 2 & Day 3 & Day 4 & Day 5 \\
\hline Simple & 40 & 30 & 20 & 10 & 0 & Simple & 5 & 4 & 3 & 2 & 1 \\
\hline Medium & 30 & 25 & 15 & 10 & 0 & Medium & 5 & 3 & 1 & 0 & 0 \\
\hline
\end{tabular}

17 For more details, consult the directive $\mathrm{n}^{\circ} 2 / \mathrm{G} / 2010$ on the practice of stress tests by banks. 


\begin{tabular}{|l|l|l|l|l|l|l|l|l|l|l|l|}
\hline High & 40 & 30 & 20 & 0 & 0 & High & 3 & 1 & 0 & 0 & 0 \\
\hline Discount & Day 1 & Day 2 & Day 3 & Day 4 & Day 5 & Discount & Day 1 & Day 2 & Day 3 & Day 4 & Day 5 \\
\hline Simple & $*$ & $*$ & $*$ & $*$ & $*$ & Simple & $*$ & $*$ & $*$ & $*$ & $*$ \\
\hline Medium & $*$ & $*$ & $*$ & 1 & 2 & Medium & $*$ & 2 & 3 & 4 & 5 \\
\hline High & $*$ & 1 & 2 & 3 & 4 & High & $*$ & 3 & 4 & 5 & 6 \\
\hline
\end{tabular}

Presentation of results (see appendix 2)

Figure 2:-Result of liquidity stress tests in favor of CDG capital

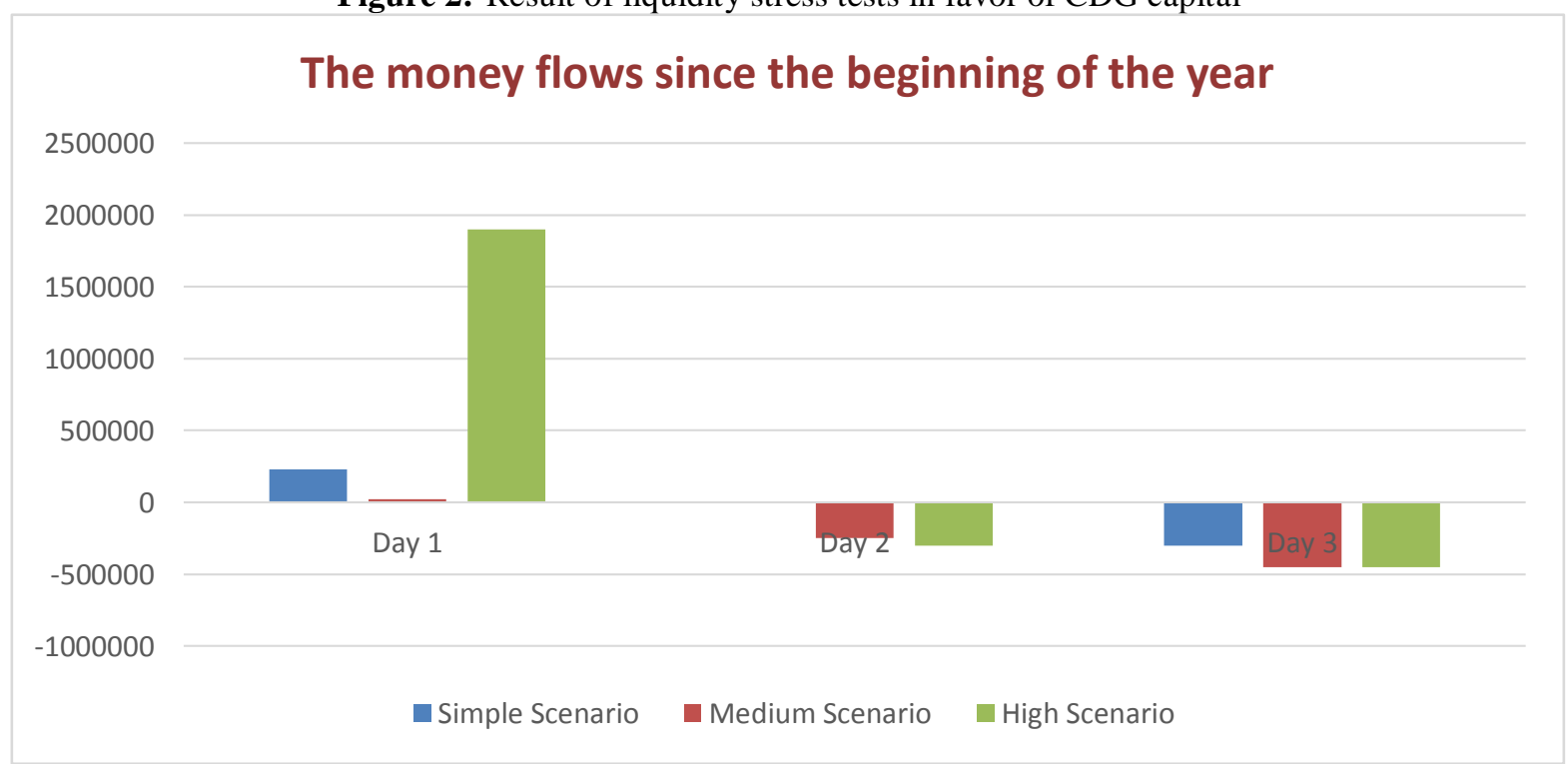

At the first day, we see that the money inflows are largely positive. This is due in the first place to the fact that the effects of the financial crisis are not felt not only in stock markets but also among depositors. Even people who are aware of the crisis still make the capital CDG's balance sheet strong and the financial system robust.

On the second day, the medium and high scenarios plunge into the negative, while the simple scenario based on assumptions with low crisis effects is only slightly positive. This is due to doubts that are starting to settle among depositors and speculators. More and more depositors withdraw their money and the financial markets succumb to the effects of doubt. A liquidation of assets which is only the consequence of a sale of a large number of assets, is born. An asset offer that is net of demand leads to a drop in asset prices and the application of several haircuts to asset prices.

On the third day, the three scenarios are red. The situation is characterized by a massive withdrawal of deposits, a forced sale and a liquidation of assets and an extreme application of haircuts. The supervisory and supervisory authority (BANK AL-MAGHRIB) is obliged to intervene to save the financial system from an insured ruin.

\section{Stress test of the liquidity ratio in the short term (L.C.R).}

\section{Presentation of the hypotheses}

The assumptions relating to the withdrawal of term and demand deposits (in national and foreign currencies) of the respective capital CDG are spread over five days as shown in Table 5:

Table 5:-table presenting LCR stress test simulation assumptions.

\begin{tabular}{|l|l|l|l|l|l|l|l|l|l|l|l|}
\hline Stable Deposit & \multicolumn{10}{l|}{ Less stable deposit } \\
\hline Scenario & Day 1 & Day 2 & Day 3 & Day 4 & Day 5 & Scenario & Day 1 & Day 2 & Day 3 & Day 4 & Day 5 \\
\hline Simple & 90 & 90 & 80 & 75 & 65 & Simple & 5 & 10 & 15 & 30 & 40 \\
\hline Medium & 90 & 80 & 70 & 60 & 100 & Medium & 10 & 20 & 30 & 45 & 0 \\
\hline High & 80 & 65 & 45 & 100 & 100 & High & 25 & 30 & 45 & 100 & 0 \\
\hline
\end{tabular}


The assumptions relating to the sales of CDG Capital's assets, as well as the respective haircuts, are spread over five days as shown in Table 6:

Table 6:-table presenting LCR stress test simulation assumptions.

\begin{tabular}{|c|c|c|c|c|c|c|c|c|c|c|c|}
\hline \multicolumn{6}{|c|}{ Very liquid assets -A1- } & \multicolumn{6}{|c|}{ Liquid Assets -2A- } \\
\hline Scenario & Day 1 & Day 2 & Day 3 & Day 4 & Day 5 & Scenario & Day 1 & Day 2 & Day 3 & Day 4 & Day 5 \\
\hline Simple & 40 & 30 & 2 & 010 & 0 & Simple & 5 & 10 & 15 & 20 & 25 \\
\hline Medium & 3 & 025 & 15 & 10 & 0 & Medium & 10 & 25 & 35 & 45 & 60 \\
\hline High & 40 & 30 & 20 & 0 & 0 & High & 25 & 35 & 40 & 55 & 70 \\
\hline \multicolumn{6}{|l|}{ Discount } & \multicolumn{6}{|l|}{ Discount } \\
\hline & $*$ & $*$ & $*$ & $*$ & $*$ & & $*$ & $*$ & $*$ & $*$ & $*$ \\
\hline & $*$ & $*$ & $*$ & 1 & 2 & & $*$ & $*$ & 1 & 2 & 3 \\
\hline & $*$ & 1 & 2 & 3 & 4 & & $*$ & 2 & 3 & 4 & 5 \\
\hline
\end{tabular}

\begin{tabular}{|l|l|l|l|l|l|}
\hline Assets that are not liquid or poorly liquid-2B- & 4 & 3 & 2 & 1 \\
\hline Simple & 5 & 3 & 1 & 0 & 0 \\
\hline Medium & 5 & 1 & 0 & 0 & 0 \\
\hline High & 3 & \multicolumn{5}{l|}{} \\
\hline Discount & $*$ & $*$ & $*$ & $*$ & $*$ \\
\hline Simple & $*$ & $*$ & $*$ & 1 & 2 \\
\hline Medium & $*$ & 1 & 2 & 3 & 4 \\
\hline High & $*$ & & \\
\hline
\end{tabular}

\section{V.2.2 Presentation of LCR results (see Appendix 3)}

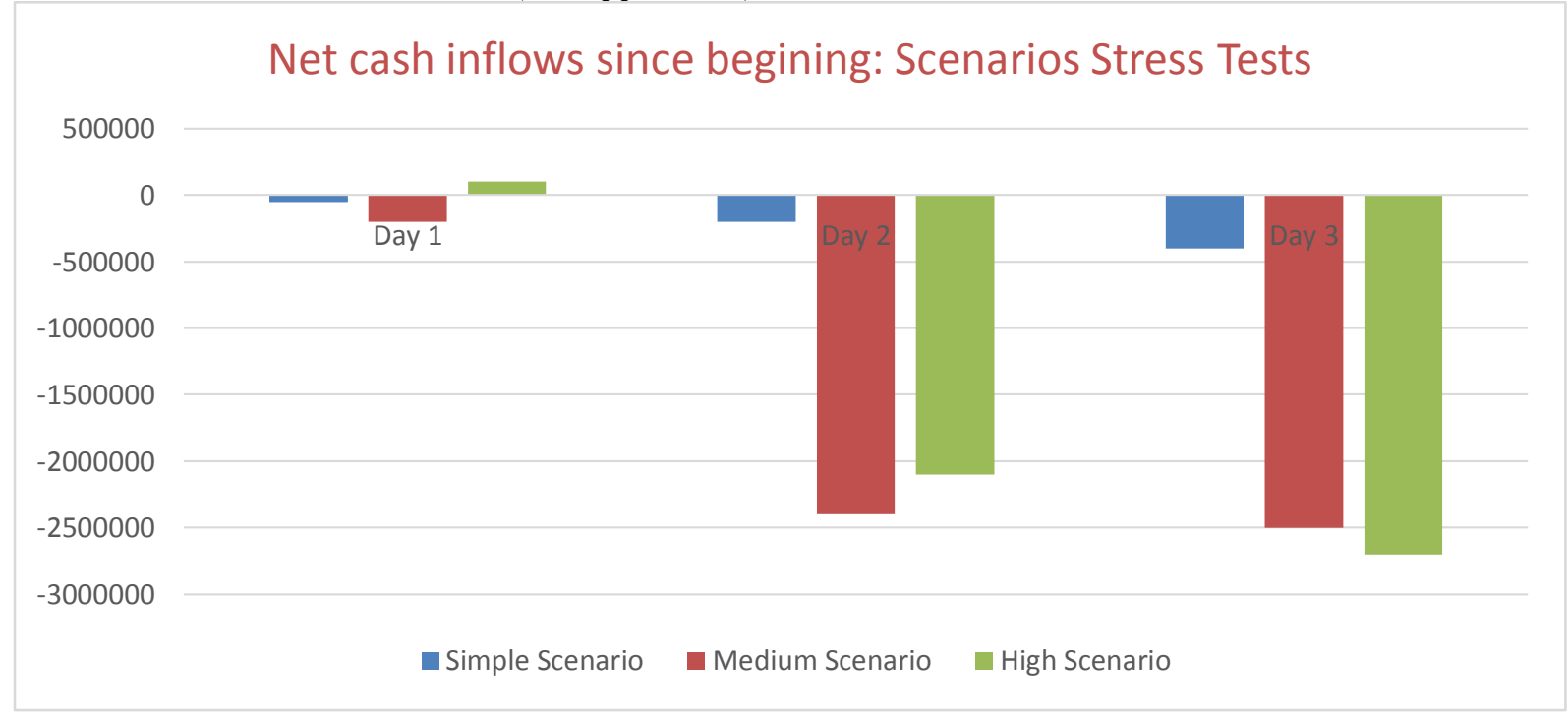

Figure 10:-Result of stress tests on short-term liquidity ratio in favor of CDG Capital

At the first day level, there is a slight decrease in inflows of money. This is due in the first place to the fact that the effects of the financial crisis are not felt not only in stock markets but also among depositors. Even the people who are aware of the crisis are still the strength of the capital CDG balance sheet and the robustness of the financial system.

On the second day, the medium and high scenarios plunge into the negative, while the simple scenario based on assumptions with low crisis effects is only slightly positive. This is due to doubts that are starting to settle among depositors and speculators. More and more depositors withdraw their money and the financial markets succumb to the effects of doubt. A liquidation of assets which is only the consequence of a sale of a large number of assets, is born. An asset supply that is well above demand leads to a drop in asset prices and the application of several haircuts to asset prices. 
On the third day, the three scenarios are red. The situation is characterized by a massive withdrawal of deposits, a forced sale and a liquidation of assets and an extreme application of haircuts. The supervisory and supervisory authority (BANK AL-MAGHRIB) is obliged to intervene to save the financial system from an insured ruin.

\section{Conclusion:-}

For each type of risk (interest rate risk, market risk, foreign exchange risk, credit risk, liquidity risk, etc.), it is necessary to decide on the type of stress test to be carried out (sensitization). the scenario, the extreme value, the maximum loss), the type of shock to be applied (to individual market variables, underlying volatility or correlations), the type of scenario to consider (hypothetical, historical simulation, Monte Carlo); as well as the assets must be shocked by how much, and over what period of time. For an overall stress test, it is also important to decide which institutions to include in the analysis, and how to aggregate, present and interpret the results ${ }^{18}$.

In its simplest form, a stress test is a way of reassessing a portfolio using a set of different assumptions. The results of a stress test show the sensitivity of the wallet to a particular shock, or a set of shock following the methodology used (stress test of scenes or sensitivity) extreme but plausible. Stress tests can be useful because for most asset markets, the history of returns does not provide enough information about the markets' behavior under extreme events. Stress tests complement traditional models with estimates of how the value of a portfolio changes in response to the exceptional but plausible changes in the underlying risk factors.

We will see throughout this chapter a definition and a conceptual framework of stress testing in the first section. A definition of the role and coverage of a stress test. In the third section a spread of the different types of stress tests and in the fourth section the methodology for the conduct of a stress test.

In the last section, a practical application of the stress tests to the case of CDG capital at the liquidity ratio level as well as the short-term liquidity ratio, with an interpretation of the results obtained.

\section{Bibliography:}

1. Kupiec, P. Techniques for Verifying the Accuracy of Risk Management Models, Journal of Derivatives; (1995).

2. Blaschke et al. Stress Testing of Financial Systems: An Overview of Issues, Methodologies, and FSAP Experiences, International Monetary Fund, IMF Working Papers (2001)

3. Aikman, David, Piergiorgio Alessandri, Bruno Eklund, Prasanna Gai, Sujit Kapadia, Elizabeth Martin, Nada Mora, Gabriel Sterne and Matthew Willison, " Funding Liquidity Risk in a Quantitative Model of Systemic Liquidity ". Bank of England, working paper, June, No. 372. (2009).

4. http://www.cssf.lu/fr/ue-international/autorites-ue/eba/eu-wide-stress-testing-and-transparency-exercise/2011stress-test-and-recapitalisation-exercise/2011-stress-test/

5. Andrew G Haldane : Rethinking the financial network 28 April (2009).

6. Borio, Claudio, Mathias Drehman, and Kostas Tsatsaronis, « Stress-testing Macro Stress Testing: Does it Live up to Expectations? " || BIS Working Paper No. 369 (2012).

7. Li Lian Ong and Martin Čihák International Monetary Fund IMF Working Paper Monetary and capital Markets Department of Runes and Sagas: Perspectives on Liquidity Stress Testing Using an Iceland Example (2010).

8. Breuer et al., How to Find Plausible, Severe, and Useful Stress Scenarios (2009).

9. Gorton, Measuring Systemic Risk-Adjusted Liquidity (SRL): A Model Approach (2009).

10. Brunnermeier, M. K and L. H. Pedersen, "Market Liquidity and Funding Liquidity," CEPR Discussion Papers 6179, C.E.P.R. Discussion Papers 2007.

11. Li Lian Ong and Martin Čihák International Monetary Fund IMF Working Paper Monetary and Capital Markets Department of Runes and Sagas: Perspectives on Liquidity Stress Testing Using an Iceland Example 2010.

12. Financial Stability Board (FSB)," Shadow Banking: Scoping the issue," A Background Note of the Financial Stability Board (Basel; April) 2011 b.

13. [13]. Basel Committee Report on Banking Supervision 2012.

14. Petr Jakubík \& Gregory Sutton, 2011. "Thoughts on the proper design of macro stress tests,"

15. Buncic et Melecky: Macroprudential stress testing of credit risk: A practical approach for policy makers 2012.

16. Allen, F. and Gale, D. (2004a). "Financial Fragility, liquidity and asset prices," Journal of the European Economic Association, Vol. 2 (6), 1015-1048.

17. Allen, Franklin., and Douglas. Gale, 2000. " Financial Contagion". Journal of Political Economy No. 108 (1), pp. 1-33.

18 See Schmitz 2006, p. 137 
18. Bangia (A.), Diebold (F. X.), Schuermann (T.) and Stroughair (J. D.) (1999). "Liquidity risk, with implications for traditional market risk measurement and management", Wharton School, Working Paper, 99-06.

19. Basel Committee on Banking Supervision (BCBS), 2004, Principles for the management and Supervision of Interest Rate Risk $\|$.

20. Bervas, A. (2006), "Market Liquidity and its Incorporation into Risk Management", Banque de France, Financial Stability Review, No 8, pp. 63-79.

21. Bindseil, U., B. Weller and F. Wuertz (2003), "Central banks and commercial banks' liquidity risk management", Economic Notes, 32.1, 37-66

22. Schneider, E. Ubl, (June 2008), "Stress Tests for the Austrian FSAP: Methodology, Scenarios and Results," Financial Stability Report 15, Austrian National Bank: Vienna, 68-92

23. Hardy, Daniel, and Christian Schmieder, "Rules of Thumb for Solvency Stress Tests with a global case study," forthcoming IMF Working Paper (Washington: International Monetary Fund).

\section{Appendix:}

Appendix 1:-Liquidity in the money markets of the euro zone.

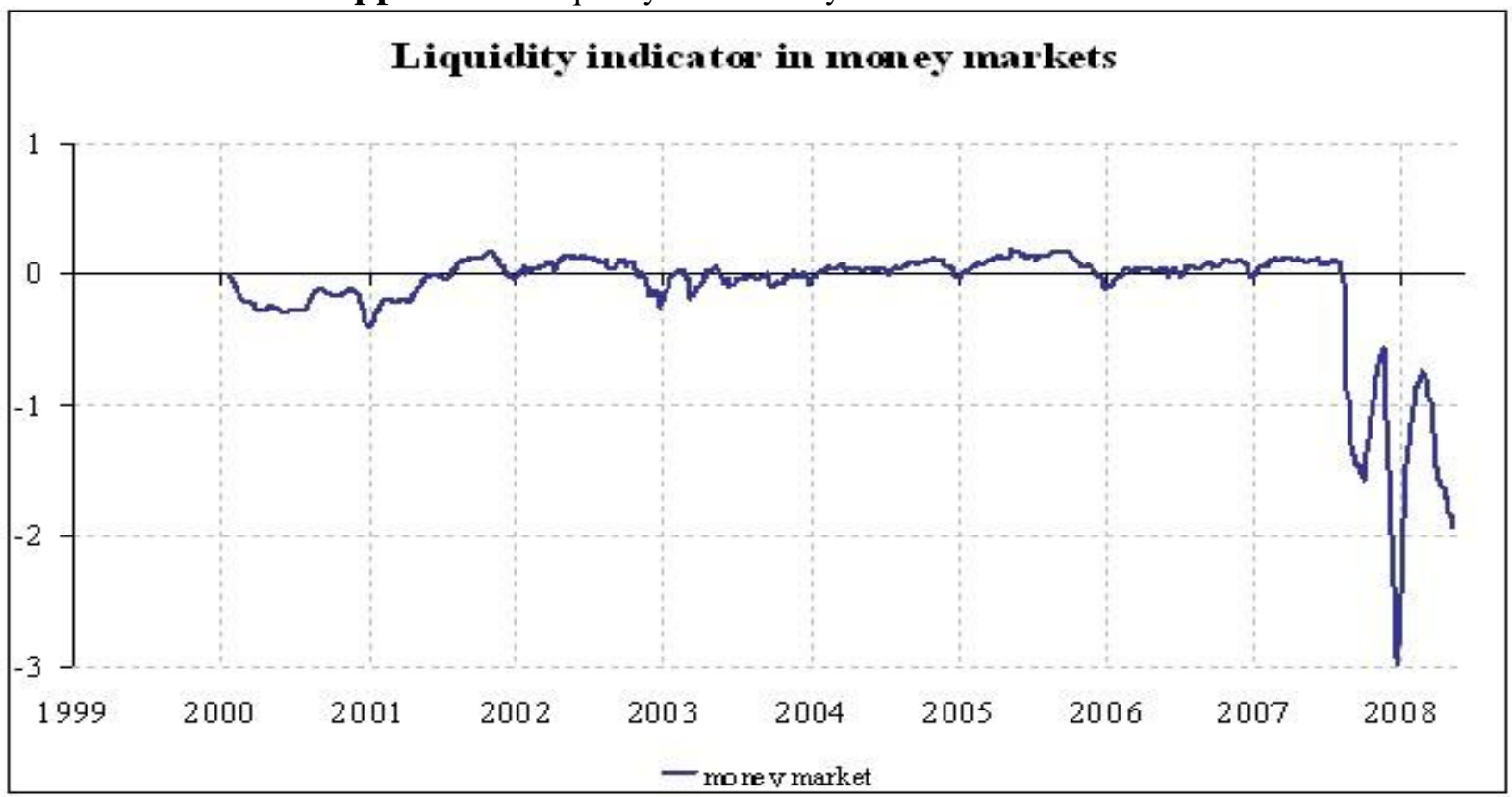

Source: European central bank. Working Paper Series, no 1008 / February 2009 Liquidity (risk). Concepts definitions and interactions. By Kleopatra Nikolao

Appendix 2:-Stress test of the liquidity ratio (based on December-2012)

\begin{tabular}{|c|c|c|c|}
\hline 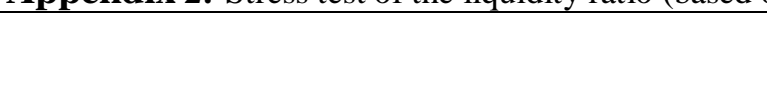 & \begin{tabular}{|l|} 
Simple \\
Scenario
\end{tabular} & $\begin{array}{l}\text { Medium } \\
\text { Scenario }\end{array}$ & High Scenario \\
\hline \multicolumn{4}{|l|}{ Day \# 1} \\
\hline Term deposit (domestic) & 1395970 & 1395970 & 1240862 \\
\hline Demand deposit (domestic) & 32616 & 65232 & 163079 \\
\hline Demand deposit (foreign) & 31205 & 29562 & 24635 \\
\hline New cash outflow (during a day) & 776450 & 745477 & 807664 \\
\hline Liquid assets (after 1 day) & 1357856 & 1584165 & 1357856 \\
\hline assets less or non-liquid (after 1 day) & 1719270 & 1719270 & 0 \\
\hline New cash inflow (during one day) & 995725 & 769416 & 2714995 \\
\hline Net cash inflow since the beginning of the year & 219275 & 23939 & 1907331 \\
\hline & $\begin{array}{l}\text { Simple } \\
\text { Scenario }\end{array}$ & $\begin{array}{l}\text { Medium } \\
\text { Scenario }\end{array}$ & High Scenario \\
\hline
\end{tabular}




\begin{tabular}{|c|c|c|c|}
\hline \multicolumn{4}{|l|}{ Day \# 2} \\
\hline Term deposit (domestic) & 1395970 & 1240862 & 1008201 \\
\hline Demand deposit (domestic) & 65232 & 13046 & 48924 \\
\hline Demand deposit (foreign) & 28084 & 24635 & 21351 \\
\hline New cash outflow (during a day) & -29495 & 212220 & 350102 \\
\hline Liquid assets (after 1 day) & 1584165 & 1697320 & 1568323 \\
\hline assets less or non-liquid (after 1 day) & 1737368 & 1720356 & 1737911 \\
\hline New cash inflow (during one day) & -244407 & -114241 & -1948378 \\
\hline \multirow[t]{2}{*}{ Net cash inflow since the beginning of the year } & 4363 & -302522 & -391149 \\
\hline & $\begin{array}{l}\text { Simple } \\
\text { Scenario }\end{array}$ & $\begin{array}{l}\text { Medium } \\
\text { Scenario }\end{array}$ & High Scenario \\
\hline \multicolumn{4}{|l|}{ Day \# 3} \\
\hline Term deposit (domestic) & 1240862 & 1085755 & 853093 \\
\hline Demand deposit (domestic) & 97847 & 195695 & 293542 \\
\hline Demand deposit (foreign) & 27920 & 21351 & 19708 \\
\hline New cash outflow (during a day) & 122656 & -24256 & -87868 \\
\hline Liquid assets (after 1 day) & 1810474 & 1923629 & 1774265 \\
\hline assets less or non-liquid (after 1 day) & 1755465 & 1737911 & 1737368 \\
\hline New cash inflow (during one day) & -244407 & -243864 & -205399 \\
\hline Net cash inflow since the beginning of the year & -362700 & -522130 & -508679 \\
\hline
\end{tabular}

Appendix 3: -Stress test du L.C.R (based on December-2012)

\begin{tabular}{|c|c|c|c|}
\hline 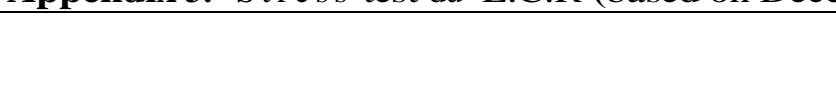 & Simple Scenario & $\begin{array}{l}\text { Medium } \\
\text { Scenario }\end{array}$ & High Scenario \\
\hline \multicolumn{4}{|l|}{ Day \# 1} \\
\hline Stable deposit & 105844 & 105844 & 211688 \\
\hline Less stable deposits & 590325 & 559256 & 466046 \\
\hline New cash outflow (during one day) & 983666 & 1014736 & 1002101 \\
\hline Very liquid assets -A1- (after a day) & 1368025 & 1596029 & 1368025 \\
\hline Liquid Assets -2A- (after one day) & 679388 & 643631 & 536359 \\
\hline Assets that are not liquid or poorly liquid-2B- (after 1 day) & 207951 & 207951 & 212329 \\
\hline New cash inflow (during one day) & 958719 & 766472 & 1097370 \\
\hline Net cash inflow since the beginning of the year & -24947 & -248264 & 95269 \\
\hline \multicolumn{4}{|l|}{ Day \# 2} \\
\hline Stable deposit & 105844 & 211688 & 370454 \\
\hline Less stable deposits & 559256 & 497116 & 434977 \\
\hline New cash outflow (during one day) & 31070 & -43705 & -127696 \\
\hline Very liquid assets -A1- (after a day) & 1596029 & 1710032 & 1580069 \\
\hline Liquid Assets -2A- (after one day) & 643631 & 536359 & 455547 \\
\hline Assets that are not liquid or poorly liquid-2B- (after 1 day) & 210140 & 214517 & 210206 \\
\hline New cash inflow (during one day) & -194436 & -2460807 & -2245792 \\
\hline Net cash inflow since the beginning of the year & -250453 & -2417103 & -2118096 \\
\hline \multicolumn{4}{|l|}{ Day \# 3} \\
\hline Stable deposit & 211688 & 317532 & 582142 \\
\hline Less stable deposits & 528186 & 434977 & 341767 \\
\hline New cash outflow (during one day) & -74774 & -43705 & -118479 \\
\hline Very liquid assets -A1- (after a day) & 1824034 & 1938036 & 2234441 \\
\hline Liquid Assets -2A- (after one day) & 607873 & 460196 & 416214 \\
\hline Assets that are not liquid or poorly liquid-2B- (after 1 day) & 212329 & 212329 & 210140 \\
\hline
\end{tabular}


New cash inflow (during one day)

$-194436$

Net cash inflow since the beginning of the year $-370114$

$-149653$

$-614973$

$-2523052$

$-2614591$

